\title{
Influence of moisture content and soil type on depth of penetration of hydrocarbons into rock massif
}

\author{
Seredin V.V. \\ Perm State National Research University \\ Russia \\ seredin@nedra.perm.ru
}

Rastegaev A.V.

Perm national research Polytechnic University

Russia

gng@pstu.ru

\author{
Galkin V.I. \\ Perm national research Polytechnic University \\ Russia \\ vgalkin@pstu.ru \\ Leonovith M.F. \\ Perm State National Research University \\ Russia \\ kafedra.ingeo@gmail.com
}

\begin{abstract}
When operating facilities of production, transportation, and storage of oil and oil products, the pollution of various objects of the natural environment happens quite often. The technogenic impact of hydrocarbons (HC) on the ground mass is of interest in two aspects at least. The first aspect is the negative impact of hydrocarbons on soils, drinking water, and air that is the components of human life. The second aspect is a change in the characteristics of soils and, as a consequence, the bearing capacity of the soil base of engineering structures. The study of the features of distribution of hydrocarbons (HC) in various soils makes it possible to assess the levels of soil contamination in case of emergency spills of oil and oil products in the territories. This is due to the fact that research objects - a soil massif and hydrocarbons - have a complex structure and different properties. That is why the issues of determination of the depth and degree of soil contamination with hydrocarbons require experimental and theoretical development. The purpose of this paper is to experimentally study the effect of moisture and soil type on the depth of hydrocarbon penetration into the soil massif and a statistical description of these processes. Engine oil was used as hydrocarbons, and sands and clays - as soils. It was found that the process of filtration of engine oil was much more intensive in medium size dry sand than that of small size dry sand and even more so that in clays. It has been established that the penetration of engine oil into sand of medium size to a depth of $26 \mathrm{~cm}$ causes considerable influence, but the moisture does not influence the depth of hydrocarbon distribution from a depth of more than $26 \mathrm{~cm}$. Mathematical models were constructed, which allow one to describe the process of penetration of engine oil into the depths in sands.
\end{abstract}

Keywords - soil; sand; engine oil; hydrocarbons; contamination

\section{INTRODUCTION}

When operating facilities of production, transportation, and storage of oil and oil products, the pollution of various objects of the natural environment happens quite often [1]. The technogenic impact of hydrocarbons (HC) on the ground mass is of interest in two aspects at least. The first aspect is the negative impact of hydrocarbons on soils, drinking water, and air [2] that is the component of human life. To reduce this effect, soil reclamation is carried out $[3,4]$. The second aspect is changes in the properties of soils when their pore fluid is replaced by hydrocarbons [5]. The study of the patterns of distribution of hydrocarbons (HC) in various soils [6], as well as papers on the experimental modelling of hydrocarbon contamination of the geological environment [7, 8], make it possible to predict soil contamination levels during oil and oil product spills [9] in restricted areas. This is due to the fact that research objects - a soil massif and hydrocarbons - have a complex structure and different properties. That is why the issues of determination of the depth and degree of soil contamination with hydrocarbons require experimental and theoretical development. The aim of this paper is to study the effect of moisture content and soil type on the penetration depth of engine oil into the soil massif.

The object of research are sands of small and medium size, as well as clays. The distilled water and engine oil "LUKOIL "Moto2T" was used as the technogenic contaminant.

\section{METHODS OF RESEARCH}

To achieve the goal, a series of experimental studies of soils in the air-dry state and at various degrees of moisture content was carried out.

Experiments were carried out in plastic pipes with diameter $\mathrm{d}=5 \mathrm{~cm}$ and height $\mathrm{h}=55 \mathrm{~cm}$. A rigid washer (piston) perforated with drainage holes with the diameter of $1.5 \mathrm{~mm}$ was placed on the bottom of the cylinder, and a filter paper liner was placed on top of it. In total, two series of experiments were carried out. For the first series, dry sand of different fractions and clay were placed in cylinders and compacted by a static load of $0.007 \mathrm{MPa}$ to full stabilization of the subsidence process.

For the second series of experiments, distilled water was poured into the cylinder with medium-sized sand until the entire volume was completely moistened. The water was filtered through the drainage holes for 3 days. After that, the soil was ready for studies. 
In the prepared cylinders with dry and moist soils, engine oil "LUKOIL "Moto2T" was poured in the volume of $100 \mathrm{ml}$. Measurements of the penetration depth of oil $(\mathrm{H})$ in wet sand were carried out using a measuring ruler with an accuracy of a tenth of a centimetre along the oil track in the ground with fixation of the observation time ( $t$, day). To assess the humidity and concentration of hydrocarbons along the height of the cylinder, soil samples were taken for chemical analysis. 48 samples were taken in total.

To calculate the coupling equations, a probabilitystatistical analysis of the information was used [5].

\section{Results of the research and their discussion}

Experimental data on the distribution of engine oil in the depth of the cylinder $(\mathrm{H})$ in time $(\mathrm{t})$ in dry and wet sand of medium size are shown in Fig. 1. It can be seen from the figure that in wet sand the filtration process proceeded much more intensively than in the case of dry sand. It was found out that at the time of pollutant intake less than 2 days the filtration process proceeded almost equally, and with the increase of the technogenic load time the process of filtration of the pollutant was sharply weakened for dry sand. It was found that the pollutant reached the bottom of the cylinder $(\mathrm{H}$ $=54 \mathrm{~cm}$ ) in wet sand after 8 days, and in the dry sand - after 41 days. So, the moisture content of the sand significantly enhances the process of filtration of the engine oil in the medium sand.

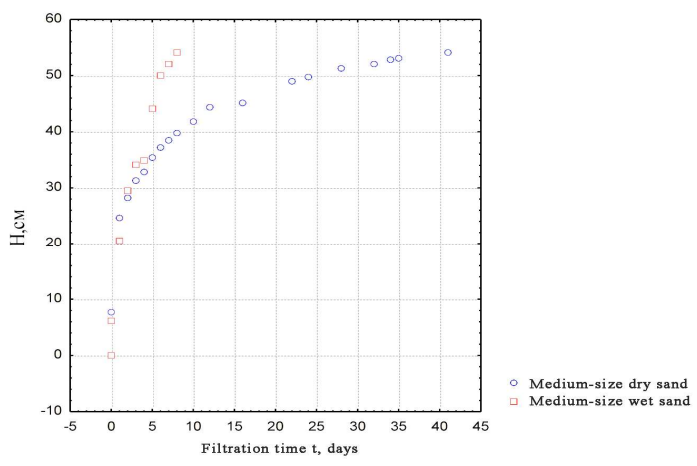

Fig.1. Distribution of engine oil in the depth of the cylinder $(\mathrm{H})$ in time $(\mathrm{t})$ for medium sand

The results of studies on the effect of the type of dry soil (sands of small, medium size and clays) on the depth of penetration of oil $\mathrm{H}$ in the cylinder are shown in Fig. 2. Hence it can be seen that the process of oil filtration proceeded much more intensively for medium size dry sand than for small size dry sand and clay.

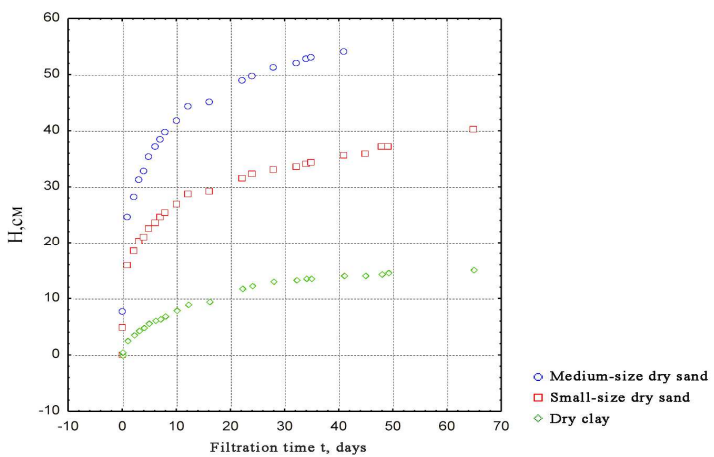

Fig.2. The influence of the type of soil (sands of small, medium size and clay) on the penetration depth of oil $\mathrm{H}$

Data on the change in moisture content $(\mathrm{W}, \%)$ in sands of medium size before $\left(\mathrm{W}^{\mathrm{H}}\right)$ and after $\left(\mathrm{W}^{\mathrm{n}}\right)$ engine oil filtration in the depth of cylinder $\mathrm{H}$ are shown in Fig. 3.

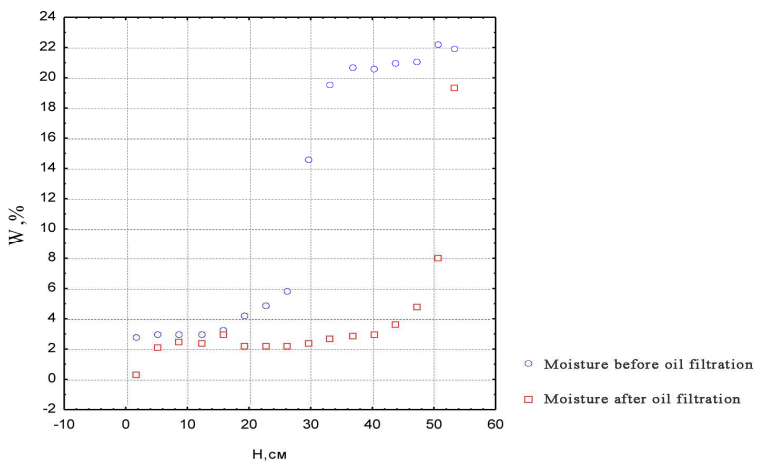

Fig.3. The change in the moisture content in sand $\mathrm{W}$ along the height of the cylinder, $\mathrm{H}$, before and after filtration of the engine oil

From this it can be seen that before the oil is filtered through the cylinder, the moisture content in the medium sands is distributed in three scenarios: the first spreads to a depth of $25 \mathrm{~cm}$, where the moisture content of the soil naturally increases with the increase of penetration depth. In the second scenario, covering the depth of the cylinder of 25$35 \mathrm{~cm}$, a sharp increase in the moisture content in sand is observed. In the third scenario, covering the depth of the cylinder more than $35 \mathrm{~cm}$, as in the first scenario, with increase of the penetration depth, the moisture content of the soil naturally increases.

After filtration of engine oil, the moisture in the medium sands is also distributed in three scenarios, but the moisture threshold value for the second scenario is $\mathrm{H}=40 \mathrm{~cm}$.

Experimental data on the change in engine oil content in wet $(\mathrm{Cw}, \%)$ and dry $(\mathrm{Cd}, \%)$ medium sand along the depth of the cylinder showed that the oil content in sand along the height of the cylinder for wet sand is somewhat lower than for dry sand. Let us note, that up to $\mathrm{H}$ less than $40 \mathrm{~cm}$, the engine oil content naturally increases, then it behaves chaotically in moist sand.

The effect of $\mathrm{W}^{\mathrm{H}}$ moisture content and engine oil content in wet $\left(\mathrm{C}^{\mathrm{w}}\right)$ and dry $\left(\mathrm{C}^{\mathrm{d}}\right)$ medium sand on the depth $(\mathrm{H})$ of penetration of hydrocarbons in the cylinder was studied. To solve this problem, the authors used multidimensional 
statistical analysis [10]. In the methodical plan, the work was carried out according to the three scenario conditions. The first scenario took into account the effect of the indicators $\mathrm{W}^{\mathrm{H}}$ and $\mathrm{C}^{\mathrm{W}}$ on the penetration depth of hydrocarbons in the cylinder; the second $-\mathrm{W}^{\mathrm{H}}$ and $\mathrm{C}^{\mathrm{d}}$; the third $-\mathrm{W}^{\mathrm{H}}, \mathrm{C}^{\mathrm{W}}$ and $\mathrm{C}^{\mathrm{d}}$. Then, for each scenario, multidimensional models were built, where the indicator " $\mathrm{H}$ " was designated as " $\mathrm{y}$ ", and indicators $\mathrm{W}^{\mathrm{H}}, \mathrm{C}^{\mathrm{d}}$, and $\mathrm{C}^{\mathrm{w}}$ - were designated as " $\mathrm{h}$ ". To calculate multidimensional models, 13 sample aggregates were used, which were built on the basis from the minimum $(n=3)$ to the maximum $(n=16)$. In each multidimensional model, the values of free terms (a), coefficients at exponents (k), coefficients of multiple correlation (R) and significance level (p) were studied. The multidimensional models built are given in the table.

Table I. Multidimensional models for calculation of $\mathrm{H}$

\begin{tabular}{|c|c|c|c|c|c|c|}
\hline \multirow{2}{*}{$\begin{array}{l}\text { The sample } \\
\text { size, } \mathrm{n}\end{array}$} & \multirow{2}{*}{ Scenario } & \multirow{2}{*}{$\begin{array}{l}\text { Free term, a-numerator, value } \mathrm{p} \text { - } \\
\text { denominator }\end{array}$} & \multicolumn{3}{|c|}{$\begin{array}{l}\text { Angular coefficients at exponents } \\
\qquad(\mathrm{k}),\end{array}$} & \multirow[t]{2}{*}{$\begin{array}{l}\text { Coefficients } \mathrm{R} \text { - numerator, value } \mathrm{p} \text { - } \\
\text { denominator }\end{array}$} \\
\hline & & & $\mathrm{W}^{\mathrm{H}}$ & $\mathrm{C}^{\mathrm{w}}$ & $C^{d}$ & \\
\hline \multirow{3}{*}{3} & 1 & $\frac{-61.294}{0.14449}$ & & $\frac{-33.2943}{0.144488}$ & & $<\underline{0.974}$ \\
\hline & 2 & $\frac{-65.375}{0.411875}$ & $\frac{24.7519}{0.388329}$ & & & $\frac{0.819}{0.14449}$ \\
\hline & 3 & $\frac{61.294}{0.132641}$ & & $\frac{-33.2278}{0.144488}$ & & $<\underline{0.974}$ \\
\hline \multirow{3}{*}{4} & 1 & $\frac{-102.375}{0.308519}$ & $\frac{32.868}{0.326638}$ & $0 . \frac{8.490}{0.492685}$ & & $<\underline{0.905}$ \\
\hline & 2 & $\frac{-161.405}{0.230388}$ & $\frac{40.84219}{0.225322}$ & & $\frac{18.185}{0.492685}$ & $<\underline{0.943}$ \\
\hline & 3 & $\frac{-151.583}{0.266975}$ & 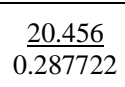 & $0 . \frac{42.922}{0.303469}$ & & $\frac{0.947}{0.33107}$ \\
\hline \multirow{3}{*}{5} & 1 & $\frac{-61.169}{0.066724}$ & $\frac{23.6375}{0.048218}$ & & & $<\frac{0.881}{0.04822}$ \\
\hline & 2 & $\frac{-61.169}{0.066724}$ & $\frac{23.6375}{0.048218}$ & & & $\frac{0.881}{0.04822}$ \\
\hline & 3 & $\frac{-18.057}{0.313387}$ & & $\frac{14.5571}{0.1571}$ & & $<\frac{0.739}{0.04822}$ \\
\hline \multirow{3}{*}{6} & 1 & $\frac{-27.594}{0.065387}$ & $0 . \frac{6.5144}{0.160078}$ & $0 . \frac{8.7879}{0.210420}$ & & $<\frac{0.916}{0.06399}$ \\
\hline & 2 & $\frac{-44.802}{0.178451}$ & $\frac{5.8170}{0.346922}$ & & $\frac{12.0867}{0.386842}$ & $<\underline{0.883}$ \\
\hline & 3 & $\frac{-21.325}{0.173786}$ & & $\frac{16.5495}{0.061451}$ & & $\frac{0.790}{0.06145}$ \\
\hline \multirow{3}{*}{7} & 1 & $\frac{-28.502}{0.025410}$ & $\frac{7.5118}{0.008325}$ & $0 . \frac{7.6954}{0.119692}$ & & $<\frac{0.946}{0.01073}$ \\
\hline & 2 & $\frac{-42.593}{0.135431}$ & $0 . \frac{4.2194}{0.331092}$ & & $\frac{12.9585}{0.292910}$ & $<\frac{0.992}{0.02240}$ \\
\hline & 3 & $\frac{-53.380}{0.075749}$ & & & $\frac{21.3073}{0.038256}$ & $<\frac{0.780}{<0.038256}$ \\
\hline \multirow{3}{*}{8} & 1 & $0 \frac{-25.10}{0.022517}$ & $0 . \frac{6.2746}{0.002008}$ & $0 . \frac{7.9654}{0.100454}$ & & $<\underline{0.954}$ \\
\hline & 2 & $\frac{-42.703}{0.064312}$ & $\frac{4.1866}{0.078014}$ & & $\frac{13.0288}{0.138401}$ & $<\underline{0.948}$ \\
\hline & 3 & $\frac{-25.850}{0.070822}$ & $\frac{5.5731}{0.016093}$ & $\frac{10.0406}{0.144296}$ & & $<\frac{0.901}{0.01531}$ \\
\hline
\end{tabular}




\begin{tabular}{|c|c|c|c|c|c|c|}
\hline \multirow{3}{*}{9} & 1 & $0 . \frac{-9.479}{544237}$ & $\frac{1.25413}{0.205387}$ & $\frac{9.22334}{0.341575}$ & & $\begin{array}{c}<.785 \\
<0.05640\end{array}$ \\
\hline & 2 & $\frac{-62.788}{0.009494}$ & $\frac{0.8223}{0.107133}$ & & $\underline{23.2959}$ & $<\underline{0.940}$ \\
\hline & 3 & $\frac{-55.230}{0.054645}$ & $0 . \frac{0.8125}{2255583}$ & & $\frac{21.1610}{0.033887}$ & $\frac{0.880}{<0.00155}$ \\
\hline \multirow{3}{*}{10} & 1 & $\frac{-10.186}{0.465523}$ & $\frac{1.1789}{0.023652}$ & 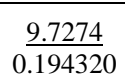 & & $\frac{0.849}{<0.01152}$ \\
\hline & 2 & $\frac{-63.770}{0.004055}$ & $\frac{0.7322}{0.022316}$ & & $\frac{23.7224}{0.002040}$ & $\frac{0.956}{0.00018}$ \\
\hline & 3 & $\frac{-56.144}{0.031776}$ & $\frac{0.7287}{0.073345}$ & & $\frac{21.5577}{0.016441}$ & $\frac{0.912}{<0.00192}$ \\
\hline \multirow{3}{*}{11} & 1 & $\frac{-10.185}{0.432855}$ & $\frac{1.1796}{0.004970}$ & $\frac{9.7251}{0.160800}$ & & $\begin{array}{c}<.889 \\
<0.00193\end{array}$ \\
\hline & 2 & $\frac{-62.070}{0.002935}$ & $\frac{0.6459}{0.019618}$ & & $\frac{23.3002}{0.001232}$ & $\underline{0.964}$ \\
\hline & 3 & $\frac{-54.705}{0.024488}$ & $\frac{0.6459}{0.019618}$ & & $\frac{21.2004}{0.011533}$ & $\frac{0.932}{<0.00018}$ \\
\hline \multirow{3}{*}{12} & 1 & $\frac{-10.147}{0.381999}$ & $\frac{1.0842}{0.004457}$ & $\frac{10.2861}{0.105158}$ & & $\begin{array}{c}<.907 \\
<0.00040\end{array}$ \\
\hline & 2 & $\frac{-43.3281}{0.033889}$ & $\frac{0.6745}{0.052796}$ & & $\frac{17.5793}{0.013740}$ & $\frac{0.939}{<0.00007}$ \\
\hline & 3 & $\frac{-43.3281}{0.033889}$ & $\frac{0.6745}{0.052796}$ & & $\underline{17.5793}$ & $\begin{array}{c}<.939 \\
<0.00007\end{array}$ \\
\hline \multirow{3}{*}{13} & 1 & 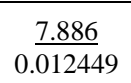 & $\frac{1.53315}{0.000017}$ & & & $\frac{0.908}{<0.00002}$ \\
\hline & 2 & $\frac{-27.8452}{0.034813}$ & $\frac{0.8619}{0.008411}$ & & $\underline{12.1973}$ & $\frac{0.955}{<0.00000}$ \\
\hline & 3 & $\frac{-41.061}{0.044747}$ & $\frac{0.7023}{0.048278}$ & $\frac{-1.3300}{0.228759}$ & $\frac{17.6723}{0.020949}$ & $\frac{0.950}{<0.00007}$ \\
\hline \multirow{3}{*}{14} & 1 & $0 . \frac{6.544}{029140}$ & $\frac{1.416103}{0.000092}$ & $\frac{0.924360}{0.002860}$ & & $\begin{array}{c}<.932 \\
<0.00002\end{array}$ \\
\hline & 2 & $\frac{-20.036}{0.037811}$ & $\frac{0.9612}{0.002406}$ & & $\frac{9.5972}{0.006657}$ & $\begin{array}{c}<.960 \\
<0.00007\end{array}$ \\
\hline & 3 & $\frac{-37.196}{0.041608}$ & $\frac{0.7959}{0.024346}$ & $\frac{-1.4254}{0.017823}$ & $\frac{16.4401}{0.017794}$ & $\frac{0.958}{<0.00007}$ \\
\hline \multirow{3}{*}{15} & 1 & $\frac{6.232}{0.039064}$ & $\frac{1.533399}{0.000020}$ & $\frac{0.789583}{0.246782}$ & & $\underline{<0.936}$ \\
\hline & 2 & $\frac{2.055}{0.576097}$ & $\frac{1.440228}{0.000024}$ & & $\underline{1.975733}$ & $\frac{0.945}{<0.00000}$ \\
\hline & 3 & 0.515302 & $\frac{1.259388}{0.000392}$ & $\frac{0.716731}{0.274996}$ & $\frac{1.862061}{0.109717}$ & $\begin{array}{l}<.944 \\
<0.00001\end{array}$ \\
\hline \multirow{3}{*}{16} & 1 & $0 . \frac{6.752}{025382}$ & $\frac{1.772402}{0.000000}$ & & & $\frac{0.931}{<0.00000}$ \\
\hline & 2 & $\frac{1.931}{0.619185}$ & $\frac{1.539522}{0.000010}$ & & $\underline{1.863921}$ & $\begin{array}{c}<.944 \\
<0.14449\end{array}$ \\
\hline & 3 & $0 . \frac{2.900}{0.475355}$ & $\frac{1.590875}{0.000020}$ & & $\frac{1.863066}{0.125024}$ & $\frac{0.937}{0.14449}$ \\
\hline
\end{tabular}


Hence it can be seen that the indicator $\mathrm{W}^{\mathrm{H}}$ index is present in all the models built, while indicators $C^{\mathrm{w}}$ and $\mathrm{C}^{\mathrm{d}}$ are only in a number of models. So, to analyse the data obtained, a graph of the change in the coefficients " $\mathrm{k}$ " at indicator $\mathrm{W}^{\mathrm{H}}$ is built for three scenarios (variants) with respect to $\mathrm{H}$ (Fig. 4).

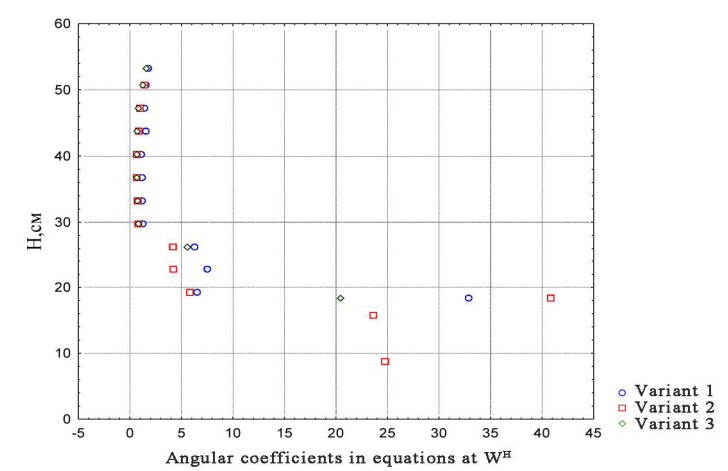

Fig.4. Changes in the angular coefficients "k" at indicator $\mathrm{W}^{\mathrm{H}}$ in three scenarios (variants) relative to $\mathrm{H}$

From this it can be seen that up to depth $\mathrm{H}<26 \mathrm{~cm}$, there are differences in the values of the coefficients at $\mathrm{W}^{\mathrm{H}}$; further, the values of the coefficients almost do not change. This indicates that the moisture content will have a significant effect on the penetration of engine oil into medium sand to a depth of $26 \mathrm{~cm}$, and from a depth of more than $26 \mathrm{~cm}$, the moisture content does not influence indicator $\mathrm{H}$.

Changes in the values of multiple correlation coefficient $R$ as a function of $\mathrm{H}$ show that for wet sand, the $\mathrm{H}$ and $\mathrm{R}$ ratio is characterized by two subfields, the boundary between which is at $\mathrm{H}=26 \mathrm{~cm}$. For dry sand, this boundary is also observed. When $\mathrm{H}<26 \mathrm{~cm}$, there is a fairly close correlation between $\mathrm{H}$ and $\mathrm{R}$; when $\mathrm{H}>26 \mathrm{~cm}$, the correlation is disturbed. This shows that the penetration of oil in medium sands depends on the moisture content to a depth of $26 \mathrm{~cm}$, then this effect is not observed.

\section{CONCLUSION}

1. The moisture content of soil enhances the process of filtration of engine oil in medium sand significantly.
2. The process of filtration of engine oil was much more intensive in medium-size dry sand than small-size dry sand and even more so in clays.

3. Mathematical models have been built that allow studying the process of penetration of engine oil in sands.

4. This shows that the penetration of oil in medium sands depends on the moisture content to a depth of $26 \mathrm{~cm}$; then this effect is not observed.

\section{References}

[1] A.A. Oborin, Oil-contaminated biogeocenosis, Perm, Perm State Technical University, 2008.

[2] I.H. Gomes, C. Dias-Ferreira, A.B. Ribeiro, "Overview of in situ and ex situ remediation technologies for PCB-contaminated soils and sediments and obstacles for full-scale application," Science of the Total Environment, vol. 445-446, pp. 237-260, 2013.

[3] Y. I. Pikovsky, "Transformation of technogenic oil flows in soil ecosystems," Restoration of oil-contaminated soil ecosystems, Moscow, Nauka, 1988, pp.7-31.

[4] A. Kessler, H. Rubin, Relationships between water infiltration and oilspill migration in sandy soils, J. Hydrol, vol.91, pp.187-204, 1987.

[5] V.V. Seredin, A.O. Starodumova, M.V. Pushkareva, L.O. Leibovich, "Experimental study of the distribution of hydrocarbon contamination in the geological environment," Oil industry, vol. 10, pp. 131-133, 2014.

[6] K.L. Foster, G.A. Stern, J. Carrie, J.N.-L. Bailey, P.M. Outridge, H. Sanei, R.W. Macdonald, "Spatial, temporal, and source variations of hydrocarbons in marine sediments from Baffin bay, eastern Canadian Arctic," Science of the Total Environment, vol. 506-507, pp. 430-443, 2015.

[7] V.P. Seredina, A.I. Nepotrebniy, S.A. Ognev, "Peculiarities of migration of oil products in podzolic soils of the middle taiga of Western Siberia", Modern problems of the humanities and natural sciences, Materials of the XXI International Scientific and Practical Conference, pp. 85-89, 2014.

[8] I.V. Krupoderov, V.V. Moiseiskin, "Modelling of hydrocarbon contamination of geological environment in the territory of Voranezh oil base of JSC "Voranezhnefteproduct," Mining informational and analitical bulletin, vol. 11, pp. 273-281, 2012.

[9] O.A. Guseva, N.P. Solntseva, "Modelling of oil bearing and oil yielding capacities tundra landscape soils at the European part of Russia (EPR)," IV Int. symp. on the geochemistry of the Earth's surface, pp.417-420, 1996.

[10] K.H. Esbensen, Multivariate Data Analysis In Practice, 5-th. ed. CAMO, 2006 